\title{
Editorial
}

\section{Telemedicine to promote mental health conditions in Bangladesh during COVID-19 pandemic}

\author{
M. Yeasin Arafat ${ }^{1}$, Abhijeet Roy ${ }^{2 *}$ \\ ${ }^{1}$ Department of Public Health, North South University (NSU), Dhaka, Bangladesh \\ ${ }^{2}$ School of Pharmacy and Public Health, Independent University Bangladesh (IUB), Dhaka, Bangladesh \\ Received: 15 December 2020 \\ Accepted: 15 January 2021 \\ *Correspondence: \\ Dr. Abhijeet Roy, \\ E-mail: dr.abroy.rpmc38@gmail.com
}

Copyright: (C) the author(s), publisher and licensee Medip Academy. This is an open-access article distributed under the terms of the Creative Commons Attribution Non-Commercial License, which permits unrestricted non-commercial use, distribution, and reproduction in any medium, provided the original work is properly cited.

The coronavirus disease 2019 (COVID-19) is a disease caused by the outbreak of a new virus, known as severe acute respiratory syndrome coronavirus 2 (SARS-CoV2). On 11 March 2020, the World Health Organization (WHO) declared the COVID-19 as a global pandemic. ${ }^{1}$ The first confirmed cases were recorded in Bangladesh on 08 March 2020 and continued to spread. ${ }^{2}$ Since then, the new realities of work from home, temporary unemployment, home-schooling of children, and lack of physical contact with other family members, friends, and colleagues are taking time to habitual with it. The aftermath of such an outbreak is not only harming physical health but also mental health. ${ }^{3}$ Therefore it is necessary to identify mental health contexts of COVID19 and effective therapies to tackle the situations. ${ }^{4}$ The COVID-19 pandemic has made a significant change in the healthcare delivery system worldwide, physicians are offering digital health solutions at record, and putting the telemedicine services (i.e. telehealth) at center stage. ${ }^{5}$ With telemedicine's help, the burden of mental health can be reduced conveniently during this pandemic. ${ }^{6}$ Like other countries, Bangladesh has also started telemedicine health services to help the patient psychologically, though there are several barriers to get advantages of this approach. ${ }^{7}$ This article aims to provide an overview of the importance and necessity of telemedicine in addressing mental health conditions during the COVID-19 pandemic, particularly in Bangladesh.

The population's mental health has been dramatically affected in the last few months due to lockdown, isolation. A recently published paper regarding telemedicine's role in reducing the mental health burden from COVID-19 mentioned that several countries across the world, including China, Singapore, and Australia, are concerned about the psychological health of the people during this pandemic situation and its long-term effects. To prevent the harmful effects, they have implemented a telemedicine services. ${ }^{6}$ Several factors like job insecurity, less income, social taboo, social panicking is triggering psychological disturbances like anxiety, fear, stress, and panic. However, these burdens are being successfully mitigated by treating people with the help of telemedicine through videoconference, e-mail, telephone, or the use of smartphone apps. ${ }^{6}$

Telemedicine has had a positive outcome in several epidemics and played a significant role in treating mental health problems. ${ }^{8}$ For example, in 2014-2016, Africa was combating the Ebola crisis using a mobile app named Ebola contact tracing (ECT), which helped remotely monitoring and contact tracing of confirmed Ebola virus disease cases. In 2003, teleconsultation was used in Taiwan to treat severe acute respiratory syndrome (SARS) by using a software-based treatment that minimized the cost, travel burden and also secured the health safety of the staff. The Swiss Centre for Telemedicine, 'Medgate' was effective against influenza-like symptoms in Switzerland. ${ }^{9}$

Evidences suggest that, a nation suffers from diverse type of mental health issues like anxiety, isolation, fear, depression, panic, and sleep disturbance due to the COVID-19 pandemic. A recently published paper from Lebanon described that, the stress level has significantly increased in both symptomatic and asymptomatic COVID19 affected people. ${ }^{10}$ Both COVID-19 infected and noninfected people are equally prone to have mental health disorders during this pandemic. More than one-third of 
people in China had generalized anxiety disorders in the rapid rise period, $18 \%$ of the population suffered from a depressive illness, and similar persons had low sleep quality, the majority of them were younger age less than 35 years. ${ }^{11}$ Also, increasing the number of attacks on medical staff creates a sense of "collective hysteria". ${ }^{12}$

Psychological reactions like fear, depression, anxiety, sleep disturbances, suicidal thought, and contralateral guilt to one another are spreading among the Bangladeshi people in response to the COVID-19 pandemic. Telemedicine is the ideal choice and it should practice not only in the emergency condition but also in usual practice. ${ }^{13}$ There are numerous advantages of telemedicine to tackle down the mental health issues in the COVID-19 situation. With telemedicine's help, patients need care for anxiety and depression can be assisted without visiting a hospital, and therapy can be provided via the internet; without consultation with the doctor. Moreover, for the aged population with mental illnesses, reducing the number of hospital visits influence the reduction of secondary or tertiary infections. It is also helpful for improved professional education, quality control of screening programs, reduced health care costs. ${ }^{14}$ In addition, telemedicine might be an ideal solution to reduce the chance of spreading infection among clinicians and patients while still providing care, especially in Bangladesh where there is shortages of mental health professionals. $^{10}$

Telemedicine practices in Bangladesh commenced through the centre for rehabilitation of paralyzed (CRP) with the funding of the Swinfen Charitable Trust of the UK in $1999 .{ }^{15}$ It was documented that $94.80 \%$ specialized doctors, $74 \%$ general physicians, $91.42 \%$ patients and $80.32 \%$ of pharmacy owners want to introduce telemedicine services for the significant number of rural people in Bangladesh. ${ }^{16}$ However, there are challenges to its implementation. Studies have been conducted in Bangladesh to identify the barriers to providing telemedicine services in rural areas, identified several factors like lack of organizational effectiveness, information and communication technology infrastructure, quality of the services, resource allocation, health staff motivation, patient satisfaction, and trustworthiness. ${ }^{5}$ Technologies for telemedicine support require adequate bandwidth support for the transmission of data, images, and sound. Consequently, broadband access is essential for telemedicine. These factors raise challenges for the rural people, those without internet access, or vulnerable groups who cannot afford internet. ${ }^{17}$

Telemedicine is essential for Bangladesh to bridge the doctor-patient gap as there are very few doctors compared to the population here. The country currently has only 6 doctors for every 10,000 citizens. ${ }^{18}$ This is exceptionally problematic because about $64 \%$ of the population resides in rural areas. In contrast, $43 \%$ of the total physicians in Bangladesh reside in the capital city; Dhaka. ${ }^{15}$ Notably, in this pandemic situation, the rural people are deprived of appropriate treatment as they cannot move to the city due to travel restrictions. The application of telemedicine can be a proper solution to this. Telemedicine can improve both the quality and the access to health care service delivery with reduced costs even in low resource settings. ${ }^{19}$ Telemedicine can reduce waiting times for patients and can be economically beneficial for the health system operations. It can also improve inter-departmental and inter-hospital communication and collaboration, it can also provide opportunities for sharing best practices among physicians within Bangladesh and international hospitals, and can enhance better resource allocation. ${ }^{20}$ With telemedicine's help, existing health facilities in Bangladesh can effectively provide health services to the huge number of populations in rural Bangladesh. In this recent situation, many doctors association, private hospitals along with the government have started telemedicine service. ${ }^{21}$ This service significantly promotes people's physical and mental health by reducing depression, anxiety, and fear. ${ }^{5}$ Despite of having some limitations, telemedicine is perfectly suitable to treat the mental health problems of the people in this pandemic situation without increasing the risk of infection, promoting health, and prolonging life as well.

\section{REFERENCES}

1. The WHO Just Declared Coronavirus COVID-19 a Pandemic | Time. Available at: https://time. com/5791661/who-coronavirus-pandemicdeclara tion/. Accessed on: 19 October 2020.

2. Timeline of the COVID-19 pandemic in Bangladesh. In: Wikipedia. 2020. Available at: https://en.wikipedia.org/w/index.php?title=Timeline _of_the_COVID-19_pandemic_in_Bangladesh\& oldid=979039963. Accessed on: 24 October 2020.

3. COVID-19 and mental health. Available at: https://www.who.int/westernpacific/emergencies/co vid-19/information/covid-19-mental-health.

Accessed on: 24 October 2020.

4. Khan S, Siddique R, Li H, Ali A, Shereen MA, Bashir $\mathrm{N}$, et al. Impact of coronavirus outbreak on psychological health. J Glob Health. 2020;10(1):1-6.

5. Telemedicine is an important aspect of healthcare services amid COVID-19 outbreak: Its barriers in Bangladesh and strategies to overcome. ResearchGate. Available at: https://www.research gate.net/publication/343954777_Telemedicine_is_a n_important_aspect_of_healthcare_services_amid_ COVID-

19_outbreak_Its_barriers_in_Bangladesh_and_strate gies_to_overcome. Accessed on: 19 October 2020.

6. Zhou X, Snoswell CL, Harding LE, Bambling M, Edirippulige S, Bai X, et al. The Role of Telehealth in Reducing the Mental Health Burden from COVID19. Telemed E-Health. 2020;26(4):377-9.

7. Covid-19 telemedicine service launched. Available at: https://thefinancialexpress.com.bd/health/covid19-telemedicine-service-launched-1591415283. Accessed on: 24 October 2020. 
8. Stuijfzand S, Deforges C, Sandoz V, Sajin CT, Jaques C, Elmers J, et al. Psychological impact of an epidemic/pandemic on the mental health of healthcare professionals: a rapid review. BMC Public Health. 2020;20(1):1230.

9. Keshvardoost S, Bahaadinbeigy K, Fatehi F. Role of Telehealth in the Management of COVID-19: Lessons Learned from Previous SARS, MERS, and Ebola Outbreaks. Telemed E-Health. 2020;26(7):850-2.

10. Whaibeh E, Mahmoud H, Naal H. Telemental Health in the Context of a Pandemic: the COVID-19 Experience. Curr Treat Options Psychiatry. 2020;7(2):198-202.

11. Huang Y, Zhao N. Generalized anxiety disorder, depressive symptoms and sleep quality during COVID-19 outbreak in China: a web-based crosssectional survey. Psychiatry Res. 2020;288:112954.

12. Lima CKT, Carvalho PM de M, Lima I de AAS, Nunes JVA de O, Saraiva JS, de Souza RI, et al. The emotional impact of Coronavirus 2019-nCoV (new Coronavirus disease). Psychiatry Res. 2020;287:112915.

13. Smith AC, Thomas E, Snoswell CL, Haydon H, Mehrotra A, Clemensen J, et al. Telehealth for global emergencies: Implications for coronavirus disease 2019 (COVID-19). J Telemed Telecare. 2020;26(5):309-13.

14. Hong Z, Li N, Li D, Li J, Li B, Xiong W, et al. Telemedicine during the COVID-19 pandemic: Experiences from Western China. J Med Internet Res. 2020;22(5):1-5.

15. Telemedicine for Bangladesh: Bridging the DoctorPatient Gap [Internet]. LightCastle Partners. 2020 Available at: https://www.lightcastlebd.com/insig hts/2020/07/08/telemedicine-for-bangladesh- bridging-the-doctor-patient-gap. Accessed on: 24 October 2020.

16. A survey on the telemedicine in Bangladesh. Available at: https://www.researchgate.net/public ation/312569588_A_survey_on_the_telemedicine_i n_Bangladesh. Accessed on: 03 November 2020.

17. Leite H, Hodgkinson IR, Gruber T. New development: 'Healing at a distance'-telemedicine and COVID-19. Public Money Manag. 2020.

18. Physicians (per 1,000 people) - Bangladesh | Data. Available at: https://data.worldbank.org/indicator/ SH.MED.PHYS.ZS ?locations=BD\&display=graph-$\% 3 \mathrm{E}$. Accessed on: 24 October 2020.

19. Nessa A, Ameen MA, Ullah S, Kwak KS. Applicability of Telemedicine in Bangladesh: Current Status and Future Prospects. In: 2008 Third International Conference on Convergence and Hybrid Information Technology. Busan, Korea: IEEE. 2008. Available at: http://ieeexplore. ieee.org/document/4682154/. Accessed on: 24 October 2020.

20. Sorwar G, Rahamn M, Uddin R. Cost and Time Effectiveness Analysis of a Telemedicine Service in Bangladesh. 2008.

21. Doctors' associations launch telemedicine service for Covid-19 patients [Internet]. The Business Standard. 2020. Available at: https://tbsnews.net/coronaviruschronicle/covid-19-bangladesh/doctors-associationslaunch-telemedicine-service-covid-19. Accessed on: 24 October 2020.

Cite this article as: Arafat MY, Roy A. Telemedicine to promote mental health conditions in Bangladesh during COVID-19 pandemic. Int J Community Med Public Health 2020;7:1008-10. 